\title{
PEDAGOGIA FREINET E A ESCOLA NO SÉCULO XXI: PERSPECTIVAS HUMANIZADORAS PARA O TRABALHO PEDAGÓGICO
}

\author{
PEDAGOGÍA DE FREINET Y LA ESCUELA EN EL SIGLO XXI: \\ PERSPECTIVAS HUMANIZADORAS PARA EL TRABAJO PEDAGÓGICO
}

\author{
FREINET PEDAGOGY AND THE SCHOOL IN THE 21ST CENTURY: \\ HUMANIZADORAS PERSPECTIVES FOR THE PEDAGOGICAL WORK
}

\author{
Ana Laura Ribeiro da SILVA ${ }^{1}$ \\ Elieuza Aparecida de LIMA $^{2}$ \\ Amanda VALIENGO ${ }^{3}$
}

\begin{abstract}
RESUMO: Este artigo tem como objetivo a discussão dos princípios e técnicas de ensino organizados, desenvolvidos e socializados por Freinet (1976), para a reflexão sobre como a Pedagogia pensada por este estudioso é fonte de participação ativa de adultos (professores) e crianças no ambiente escolar, desde a Educação Infantil. A discussão parte dos estudos realizados em uma tese de doutorado (SILVA, 2016). Nesta exposição, trazemos à análise algumas vivências da professora pesquisadora com crianças de duas turmas de Educação Infantil, de algumas técnicas Freinet: Roda de Conversa, Aula passeio, Jornal de parede, Livro da vida. A geração dos dados se deu pela participação ativa, pela observação e pelo registro da prática educativa. Os resultados da investigação indicam que a vivência das técnicas Freinet pode refletir em um planejamento motivador do encontro das crianças com os objetos da cultura e com outras pessoas refletindo assim em um desenvolvimento mais pleno e harmônico na infância.
\end{abstract}

PALAVRAS-CHAVE: Técnicas Freinet. Educação Infantil. Teoria Histórico-Cultural. Cooperação atividade e participação infantis.

RESUMEN: Este artículo tiene como objetivo discutir los principios y técnicas de enseñanza organizados, desarrollados y socializados por Freinet (1976), para la reflexión sobre la pedagogía pensado por este estudioso es una fuente de participación

\footnotetext{
1 Doutora em Educação (2016) pela mesma Universidade. Atualmente, Professora nos cursos de Graduação e Pós-graduação no Núcleo de Educação à Distância da Universidade Metropolitana de Santos (UNIMES) e Professora de Educação Infantil na Rede Municipal de Cubatão (SP). Email: analaurars@gmail.com

${ }^{2}$ Doutora em Educação, Professora Assistente Doutora junto ao Departamento de Didática e ao Programa de Pós-Graduação Faculdade de Filosofia e Ciências, Universidade Estadual Paulista Júlio de Mesquita Filho, Campus de Marília, SP.; Líder do "Grupo de Estudos e Pesquisas sobre Especificidades da Docência na Educação Infantil - GEPEDEI"., e membro do Grupo de Pesquisa "Implicações Pedagógicas da Teoria Histórico-Cultural". Email: aelislima2013@gmail.com

${ }^{3}$ Doutora em Educação, Professora Adjunta Doutora junto ao Departamento de Ciências da Educação, da Universidade Federal de São João Del Rei-UFSJ, Minas Gerais; Membro do Grupo de Estudos e Pesquisas sobre Especificidades da Docência na Educação Infantil - GEPEDEI. Email: ducavaliengo@gmail.com
} 
de los adultos activos (maestros) y los niños en la escuela, desde la guardería. La discusión de los estudios en una tesis doctoral (SILVA, 2016). En esta exposición, traemos al análisis de algunas experiencias investigador profesor con niños de dos clases de jardín de infancia, algunas técnicas Freinet: Rueda de conversación, Gira de Conferencias, pared Prensa, Libro de la Vida. La generación de los datos fue por la participación activa, mediante la observación y registro de la práctica educativa. Los resultados de la investigación indican que la experiencia de las técnicas Freinet puede reflejar una reunión de planificación de la motivación de los niños con la cultura de los objetos y con los demás, así que reflejan un desarrollo pleno y armónico de la niñez.

PALABRAS CLAVE: Freinet técnica. Educación Infantil. La teoría histórico-cultural. La actividad de la cooperación y la participación de los niños.

ABSTRACT: This article aims to discuss the principles and techniques of teaching organized, developed and socialized by Freinet (1976), to reflect on how Pedagogy thought by this scholar is a source of active participation of adults (teachers) and children in the school environment, Since Early Childhood Education. The discussion is based on studies carried out in a doctoral thesis (SILVA, 2016). In this exhibition, we bring to the analysis some experiences of the researcher teacher with children of two classes of Early Childhood Education, some Freinet techniques: Wheel of Conversation, Aula promenade, Jornal de pared, Libro da vida. The data was generated by active participation, observation and registration of educational practice. The results of the research indicate that the experience of the Freinet techniques can reflect in a planning motivating the encounter of the children with the objects of culture and with other people reflecting in this way a more complete and harmonious development in childhood.

KEYWORDS: Freinet Techniques. Child education. Historical-Cultural Theory. Child activity and participation.

\section{Introdução}

Este artigo decorre de estudos de doutorado recentemente finalizados (SILVA, 2016), orientados por questões sobre o trabalho pedagógico em turmas de crianças da Educação Infantil e também aquelas relacionadas à docência no Ensino Superior. A investigação realizada teve por objetivo analisar a prática educativa baseada nas técnicas de ensino da Pedagogia Freinet a partir das implicações pedagógicas da Teoria Histórico-Cultural e assim trazer à discussão aspectos da atualidade desta Pedagogia para os desafios atuais da educação nestas décadas iniciais do século XXI.

Numa era tecnológica e neoliberal, a lógica do trabalho em diversos setores da sociedade, e também da educação, parece distante da perspectiva de uma formação 
humana em que a expressividade, a cooperação e a atuação ativa de cada pessoa sejam pilares das relações vividas. Nessa sociedade, a escola parece eleger o papel central de preparadora de mão de obra para ocupar funções na engrenagem social para manutenção do status quo.

No seio dessas discussões, estão reflexões sobre a atualidade das proposições da Pedagogia Freinet para o êxito da aprendizagem e desenvolvimento de cada homem e de cada mulher desde que são crianças na Educação Infantil, especialmente sobre como seus princípios e técnicas tem nos motivado a estudar e a pôr em prática, de modo consciente e intencional, possibilidades de atuação ativa e cooperativa na escola da infância. Nosso intuito com as discussões propostas a partir daqui é pensar a superação de práticas pedagógicas que antecipam o processo de escolarização com situações mecanicistas de reprodução e reconhecimento de letras e seus respectivos traçados, tendo como objeto de reflexão a prática pedagógica proposta pela professora pesquisadora às crianças sujeitos da pesquisa, fundamentada pela proposição do valor das técnicas de ensino elaboradas por Célestin Freinet para o processo de humanização na infância.

Com esse início de conversa, nosso texto é organizado em dois momentos: no primeiro, damos ênfase a princípios e aspectos das técnicas da Pedagogia Freinet, sinalizando percursos do trabalho educativo discutido na pesquisa de Silva (2016). Na sequência, trazemos resultados do estudo, com especial destaque para o que consideramos fontes para o exercício de ações e atitudes ativas de professores e crianças, como perspectiva de contribuições para o debate quando a questão é a atualidade da Pedagogia Freinet para a educação no século XXI, com seus desafios, tensões, necessidades e perspectivas para a humanização.

\section{Aspectos da metodologia da pesquisa: as escolhas para o percurso de estudos}

A produção de dados foi realizada mediante a participação da professora de Educação Infantil que atua junto à Prefeitura Municipal de Cubatão/SP como pesquisadora, num processo em que a geração dos dados se deu pela participação ativa, pela observação e pelo registro da prática educativa. Como professora de uma turma de crianças na Educação Infantil, professora-pesquisadora pôde ter contato direto e prolongado com a situação investigada: no caso, a prática educativa. Nesta prática, os 
sujeitos participantes do estudo se inter-relacionam e têm participação ativa sobre os dados produzidos. Ao ser agente participativo da situação, a professora-pesquisadora considera os diferentes sujeitos, inclusive a si mesma, no processo de planejamento e replanejamento da prática pedagógica. Assim, segundo Franco (2005, p. 486), “a voz do sujeito fará parte da tessitura da metodologia da investigação".

Nessa proposta metodológica, os dados da pesquisa se caracterizam não só pelas ações planejadas, mas também pelas situações que emergem das interações entre os sujeitos no próprio processo de produção dos dados.Nesse processo, foi possível compreender a práxis de uma ação educativa orientada por uma teoria que envolve o reconhecimento da dialética da realidade social, da historicidade dos fenômenos, das contradições, das relações e da ação dos sujeitos sobre suas circunstâncias (cf. FRANCO, 2005). Práxis, esta, compreendida como espaço de reflexão que une teoria e prática e possibilita ao professor a ação intencional que promove aprendizagem e desenvolvimento infantil.

A prática pedagógica, cujo registro originou os dados aqui apresentados e discutidos, teve o intuito da superação da antecipação de práticas pedagógicas alfabetizadoras pautadas na decodificação da linguagem escrita pela proposição de situações de efetivo uso desta linguagem em suas mais diversas funções sociais, em contexto planejado a partir das técnicas de ensino elaboradas por Célestin Freinet.

Essa prática pedagógica foi planejada e registrada inicialmente em semanário registro do planejamento semanal. Além desse registro, houve também o registro em diário de campo, no qual a pesquisadora fez anotações sobre o desenvolvimento das propostas, das interações entre as crianças e das marcas que ia percebendo sobre o processo de apropriação daleitura pelas crianças.

Para enriquecer e dar mais suporte aos registros do diário de campo, foram realizadas filmagens de ações específicas e algumas de situações globais do trabalho pedagógico realizado. Essas filmagens não foram transcritas na integralidade, apenas auxiliaram a observação e o registro no diário de campo. A produção de dados da pesquisa se deu por dois anos consecutivos - 2011 e 2012 - em uma Unidade Escolar da Rede Municipal da cidade de Cubatão/SP., localizada em bairro urbano,residencial e comercial, situado há seis quilômetros do Centro municipal.

A escola onde foram produzidos os dados da pesquisa aqui apresentados foi inaugurada em 1985 e, à época da elaboração dos dados, atendia à Educação Infantil com crianças de quatro e cinco anos e Ensino Fundamental com crianças de seis anos de 
idade, totalizando 300 crianças em dois períodos de atendimento.

Como já salientado, a produção de dados ocorreu durante os anos de 2011 e 2012. Em 2011, a professora pesquisadora estava trabalhando com crianças de quatro anos quando participou do processo seletivo para o Doutorado. Por causa disso, iniciou as formas de produção de dados com a intenção de testar as formas mais adequadas para sua realização. No entanto, este também era o ano de início como Servidora Pública Municipal na Rede de Ensino de Cubatão/SP e, no processo de atribuição de aulas, ainda com a função de regente, teve a oportunidade de continuar na mesma escola. Recebeu a atribuição para essa escola e pôde continuar com parte das crianças da turma do ano anterior. Decidiu, assim, a partir daí utilizar os registros do ano de 2011 e continuar a produção de dados em 2012.

As turmas compostas nos dois anos podem ser assim caracterizadas:

Turma de 2011: composta inicialmente por 19 crianças, sendo no decorrer do ano letivo contemplada com mais cinco matrículas suplementares ocorridas entre os meses de março e setembro, e uma saída por transferência ocorrida em março, totalizando 23 crianças participantes da pesquisa (14 meninas e 9 meninos). Em sua maioria, as crianças que compuseram essa classe estavam frequentando a escola pela primeira vez, tendo apenas três crianças conhecedoras da rotina e das características escolares, sendo duas oriundas de escolas particulares e uma da rede de creches municipais.

Turma de 2012: composta inicialmente por 23 crianças, sendo no decorrer do ano letivo contemplada com mais duas matrículas suplementares ocorridas nos meses de março e outubro, totalizando 25 crianças participantes da pesquisa (14 meninas e 11 meninos). Dessas, 13 crianças fizeram parte da turma observada em 2011. As demais são oriundas de outras turmas da mesma escola.

Com esse panorama do caminho percorrido para a produção dos dados, passamos, na sequência, à tessitura dos fundamentos orientadores das nossas reflexões, seguidos da discussão de resultados conquistados no estudo de Silva (2016) destacados para esta exposição.

\section{Princípios e técnicas de ensino como fundamentos para o êxito do trabalho pedagógico: resultados de pesquisa}

A partir daqui, um princípio da Pedagogia Freinet guia nossas reflexões: o "profundo respeito pela criança", articulado à perspectiva de atenção aos interesses infantis para a busca de possibilidades de atuação pedagógica cada vez mais 
humanizadora. Como é sabido, no percurso como professor, o trabalho de Freinet foi árduo, de muito estudo e observações das crianças e da comunidade local. De partilha, discussões e trabalho além da escola: criando a "cooperativa de consumo e de venda de produtos locais" (FREINET, 1978, p.33-34). Nesse envolvimento com as crianças e a comunidade, Freinet foi desenvolvendo pouco a pouco novas técnicas e formas de ensinar que ofereciam situações de envolvimento das crianças e de conhecimento efetivo dos conteúdos, não para uma exibição ou exame, mas que servia à vida observada e compreendida naquela comunidade.

São essas propostas que dão corpo ao trabalho pedagógico realizado com a turma de crianças que participou da pesquisa ora apresentada e discutida. A proposição das técnicas é um processo gradual, por meio do qual é possível observar e realizar a inserção de cada técnica no trabalho pedagógico em momentos oportunos.

Os princípios da Pedagogia Freinet podem ser retratados mediante o exercício de pensarmos a humanização em Freinet (1976). Para este estudioso, o processo de humanização é caracterizado pela ênfase no papel do tateio experimental - por meio do qual a criança forma sua inteligência e sua personalidade - e no papel do educador como parceiro mais experiente - que medeia para a criança o contato com o mundo cada vez mais amplo da cultura acumulada. Para o autor, esse processo não existe a priori na criança, nem é biologicamente dado, mas é condicionado por sua atividade social no mundo que a rodeia.

Nossas aprendizagens acerca da Pedagogia Freinet revelam que o tateio experimental é a principal fonte da aprendizagem, à medida que corresponde à necessidade da criança:

Para manipular, observar, relacionar, emitir hipóteses, verificá-las, aplicar leis e códigos, compreender informações cada vez mais complexas. É uma atitude particular que deve ser desenvolvida pouco a pouco, assim, os conhecimentos vão sendo adquiridos pela criança [...]. (SAMPAIO, 1994, p.217).

Com esse entendimento, o tateio experimental possibilita à criança ser ativa diante do conhecimento e envolve a percepção de um aspecto do processo de conhecimento que a escola, de um modo geral, parece desconsiderar: o caminho que a criança percorre a partir do conhecido em direção ao desconhecido (PODDIÁKOV, 1987), isto é, processo de aquisição autônoma de novos conhecimentos e novos dados sobre objetos e fenômenos circundantes propulsores do aperfeiçoamento autônomo dos 
procedimentos da atividade prática e cognoscitiva.

O processo de aprendizagem constitui-se, nessa ótica, como essencialmente ativoe especialmente vinculado ao conceito de trabalho. Um trabalho diferente daquele que conhecemos na sociedade capitalista, neoliberal e alienada, um fazer com sentido e objetivo, que satisfaça a necessidade de expressão e comunicação da criança; não o trabalho maçante que obriga a criança a sua execução. Nas palavras de Mello (1992, p. 77) se trata de,

Um trabalho à medida das possibilidades e necessidades da criança, que dê sentido e objetivo às aquisições e motive as criações, que proporcione autonomia na realização, promovendo auto-realização e a aprovação do grupo. Um trabalho que envolva física, afetiva e cognitivamente o aluno, favorecendo enriquecimento moral, intelectual e material do indivíduo.

$\mathrm{Na}$ escola,esse fazer é motivado pelo objetivo para a satisfação das necessidades do desejo de conhecimento da criança. Conforme Mello (1992, p. 85), "para Freinet, a aprendizagem significativa tem relação íntima com o sentimento, a afetividade, a vivência do aluno". Sobre essa questão, Freinet (1976) ensina que a aprendizagem acontece quando responde a uma necessidade da criança que aprende, porque o aprendizado tem para ela um sentido e um significado que a motiva e, por isso, a criança se envolve emocionalmente no processo.

Especialmente no que se refere à leitura e à escrita, as práticas pedagógicas tradicionais, diferentemente, parecem fundamentadas por ideias segundo as quais essas habilidades humanas seriam aprendidas por meio da exercitação do corpo, manifestadas, principalmente, por hábitos motores e pela fixação dos códigos linguísticos de forma mecânica.

Para Freinet (1976), no entanto, as aprendizagens decorrentes dessas ações (traçar as palavras, sem saber produzir textos e atribuir sentido à escrita) não têm força motora sobre o pleno desenvolvimento da inteligência e personalidade infantis, sobretudo, com referência à formação da criança como leitora e produtora de textos. Mas, então, em lugar dessas práticas, como tornar a criança sujeito ativo, capaz de atribuição de sentidos às experiências propostas na escola?

Há quase um século, um dos aprendizados de Freinet (1976), a partir de sua atuação como professor, foi que a criança não se interessa por ir à escola para copiar e ler textos de livros didáticos. Motivado por essa atitude respeitosa e sensível como 
educador na escola da infância, Freinet (1976) buscou, a partir de seus estudos e ações pedagógicas, a superação dessa prática educativa.

Com base nos princípios e técnicas Freinet, a escola pode se tornar espaço de constituição de sujeitos capazes de atuarem no mundo de maneira ativa, independente e transformadora. Na Pedagogia Freinet, estruturada por um conjunto de técnicas indissociáveis que se concretizam pela organização cooperativa, a sala referência de cada turma de crianças e todos os demais espaços da escola são lugares para o diálogo, escolhas, tateios, expressõese socialização de conhecimentos. Retomamos, assim, que, conforme o $\operatorname{ICEM}(1979$, p. 10),

O texto livre, a correspondência, o Jornal Escolar, os planos de trabalhos, as conferências, o trabalho individualizado são todos marcados com o signo da cooperação. Nenhuma dessas atividades encontra sua significação profunda se não se exercer no quadro de uma organização realmente cooperativa.

Defendemos, com essas ideias, que a cooperação acontece no conjunto complexo da vida escolar, em todas as suas organizações e relações possíveis. Freinet (apud ICEM, 1979, p.10) entende que, "pela cooperação escolar, são as crianças que efetivamente assumem a organização da atividade, do trabalho, da vida de sua escola". Com essa compreensão, numa organização cooperativa do trabalho escolar, as crianças participam de todos os processos: do planejamento, das formas de organização para a realização das atividades e da avaliação.

As técnicas de ensino elaboradas por Freinet (1976) têm, pois, sua fundamentação no grupo de invariantes pedagógicas por ele estruturadas - as técnicas educativas - que apresentam uma discussão sobre concepções motivadoras da organização de técnicas educativas que suprimissem as regras autoritárias da escola tradicional e conduzissem a um trabalho funcional para a vida das crianças.

Nesse trabalho educativo funcional, a experiência da criança - sua atividade deve ser considerada como forma privilegiada de aquisição de conhecimentos. "Não são a observação, a explicação e a demonstração - processos essenciais da escola - as únicas vias normais de aquisição de conhecimento, mas a experiência tateante, que é uma conduta natural e universal" (SAMPAIO, 1994, p. 88). Com isso, Freinet (1976) contribui para repensarmos a escola tradicional e traz um dos principais conceitos de sua pedagogia.

Vale ressaltar, nesta discussão, que a memória - assim, como as demais funções 
psíquicas -, para a Pedagogia Freinet, não tem uma utilidade em si mesma. Esta só pode ser explorada se ligada à experimentação, uma vez que essa ligação possibilita a vida em si mesma. É a vida que necessita da memória, por isso, possibilita seu desenvolvimento, e não a repetição e a técnica que a garantirão, como pensava a escola tradicional. Dito de outra maneira, as funções psicofisiológicas serão formadas e desenvolvidas no seio de atividades nas quais sejam exercitadas e necessárias (SILVA, 2016).

Sampaio (1994, p. 90) enfatiza que, para Freinet, assim como a memória é formada pela experimentação e pela vivência da criança, a inteligência não existe por si mesma: "não é uma faculdade específica, que funciona como um circuito fechado, independentemente dos demais elementos vitais do indivíduo, como ensina a escolástica". A inteligência é derivada da experiência vivida pela criança. Quanto mais diversificada for essa experiência, mais desenvolvida se faz sua inteligência. Para Freinet (1976), não se trata de uma, mas de diferentes formas de inteligência que são oriundas do tateamento experimental, isto é, da atividade da criança.

Um dos aprendizados dos estudos realizados nesses últimos anos é, nessa direção, que os pressupostos apresentados pela Pedagogia Freinet impulsionam nosso exercício de análise, conforme nos desafiamos nas páginas seguintes.

\section{Resultados e discussões sobre a vida entrando na escola}

Em relação às técnicas elaboradas por Freinet, nesta exposição, damos destaque à Roda de Conversa, Aula passeio, Jornal de parede, Livro da vida, dentre outras possíveis de reflexão, considerando os conhecimentos científicos produzidos em tese de doutorado (SILVA, 2016).

No trabalho pedagógico investigado, cujos aspectos colocamos em discussão neste texto, a Roda de Conversa acontece todos os dias na entrada/chegada das crianças à escola, em momentos de reorganização do trabalho ou em momentos de imprevistos, quando alguma coisa precisa ser conversada com todos.

É um momento de diálogo entre as crianças e da professora-pesquisadora com elas. Nesse momento, são relatados fatos e acontecimentos vividos pela turma, ou fatos observados nas imediações da escola, ou, ainda, noticiados nos meios de comunicação e que estão sendo comentados no entorno. Na rotina diária da turma, esse momento 
constitui-se em duas partes: o início do encontro com as crianças há partilha daquilo que elas querem contar aos colegas e à professora pesquisadora, e a organização das propostas do dia; e, no final do período, para avaliação do dia e análise do que foi realizado entre as propostas para aquele dia.

No momento inicial, também se realizava a Leitura diária trazida pela professora pesquisadora. Nessa leitura, amplia-se o repertório de Literatura Infantil conhecido pelas crianças com a leitura de livros, tanto do acervo da escola, geralmente oriundo das distribuições do Programa Nacional Biblioteca na Escola (PNBE), quanto do acervo pessoal da professora-pesquisadora, bem como de materiais informativos em diferentes portadores textuais. Na Roda de Conversa, também era o momento de apresentação do ajudante do dia, a definição de suas tarefas na organização do dia e espaço de partilha para os ajudantes do dia anterior relatarem as leituras realizadas com suas famílias a partir da pasta de leitura.

A imagem da sequência retrata uma situação denotativa de um momento de roda de conversa. Vejamos:

Figura 01: Criança lendo notícia trazida de casa para os colegas na Roda de Conversa Crianças de quatro e cinco anos em roda de conversa ouvindo a colega que lê uma novidade à turma.

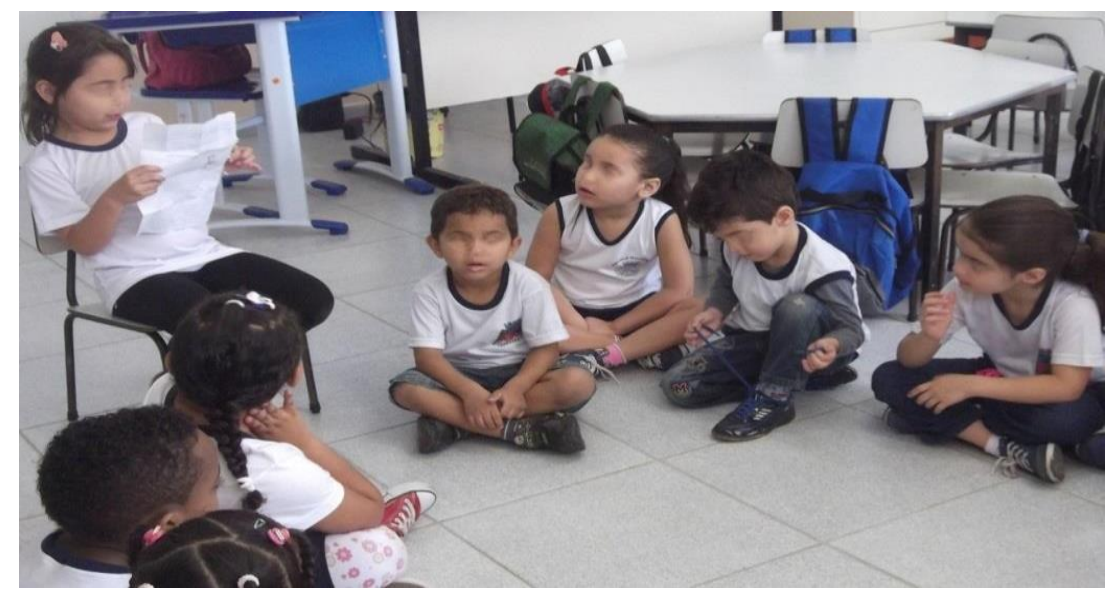

Fonte: Acervo pessoal das pesquisadoras.

Como é possível compreender, a roda de conversa cria condições para diferentes comunicações orais que possam ser realizadas a partir das vivências no dia a dia dentro e fora da escola, conforme notamos no relato transcrito abaixo em que a roda é utilizada para socializar, a partir da observação, questões sobre uma atividade 
realizada com a plantação de feijão:

Na sala, em roda de conversa, eu proponho que as crianças observem a experiência dos feijões. Ao passar os feijões pela roda, as crianças foram apontando as características de cada planta:

GCB: tem um quebrado aqui... (mostra com o dedo para outro colega) e está ficando preto.

ALVB: ela tá engraçada... ela tá querendo sair. [Refere-se à raiz observada no algodão].

JFS: Esse tá tudo branco [mostra o vaso que não recebeu luz e calor solar].

ACVC: Tia, essa parte tá de outra cor [mostra para mim a parte na planta].

[...]

GCB: Tia, eu já sei! Esse feijão verdinho [apontando o vaso que ficou exposto à luz solar] vai dar feijão e esse amarelinho vai dar milho [apontando para o vaso que foi privado de luz solar]! (Diário de Campo, 18/10/2011).

Essa técnica de ensino, roda de conversa, possibilita aprendizagens de escuta e fala, de aprendizagens cooperativas de vida, de maneira a considerar a aprendizagem da criança como processo de atuação e experiência nos próprios processos de aquisição de conhecimentos, necessariamente tendo uma criança ativa e que, portanto, aprende (FREINET, 1976).

O Jornal Escolar tem íntima relação com a Roda de Conversa. Das notícias relatadas pelas crianças na Roda de Conversa, três eram registradas na lousa pela professora-pesquisadora. Depois de registradas e discutidas cada uma das notícias, cada criança votava na de sua preferência para a impressão e registro.

A notícia escolhida era transcrita pelas crianças ajudantes do dia no computador e impressas para o registro de todas. Cada criança registrava com desenhos a sua compreensão sobre a notícia apresentada por um colega e eleita para a composição do jornal.

As notícias iam sendo arquivadas ao longo de um mês ou um mês e meio, tempo no qual se juntava aproximadamente entre 20 a 30 notícias. Era hora de levá-las para casa. Na figura 02, temos a imagem de um arquivo em que cada criança armazenava suas notícias. 
Figura 02: Arquivo de armazenagem das notícias registradas no Jornal Escolar Arquivo com pastas suspensas para arquivamento dos registros infantis para o Jornal Escolar.

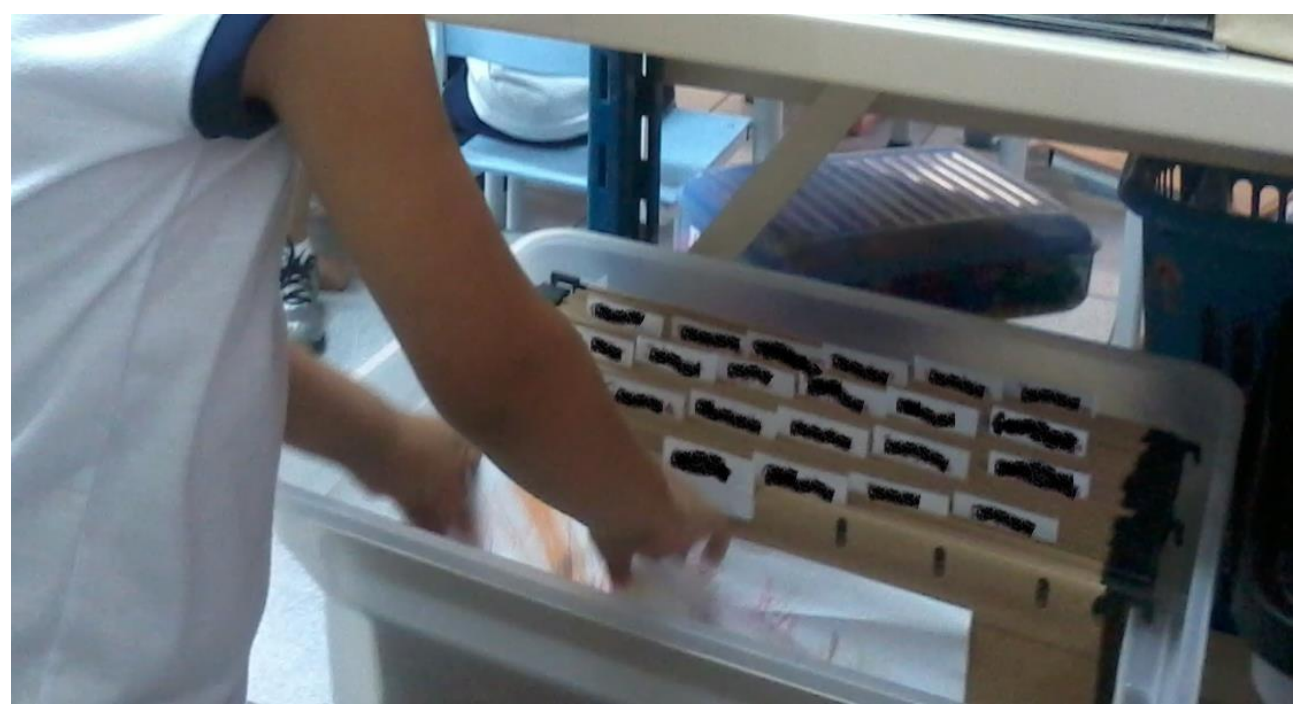

Fonte: Acervo pessoal das pesquisadora

Decorrido esse período, cada criança organiza seus registros, sob a orientação de que encontre sua notícia no jornal e que a registre na capa como sendo a manchete. Depois disso, as crianças relatam a notícia registrada na capa de seu jornal que é grampeado e levado para casa.

As famílias foram orientadas, pela professora pesquisadora em reunião de pais, sobre o recebimento desse material para que, ao recebê-lo, conversassem e questionassem as crianças sobre seus registros e sobre o que estava ali escrito. Também, foram orientadas a oferecem atenção quando as crianças solicitassem que lessem a notícia registrada. O trabalho com o Jornal Escolar foi um grande momento de interação com as famílias, pois, além da receptividade, algumas notícias registradas foram trazidas pelos pais às reuniões e possibilitaram discussão de temas sobre imaginação, brincadeira e aspectos do desenvolvimento infantil.

A figura 3 demonstra uma notícia contada por uma das crianças sobre seus pais: 
Figura 03: Desenho de uma criança sobre notícia do Jornal da Turma Proposta, realizada em 08/08/2011 para compor o Jornal Escolar. Representação (escrita e pictórica) feita por IWO de quatro anos e dez meses.

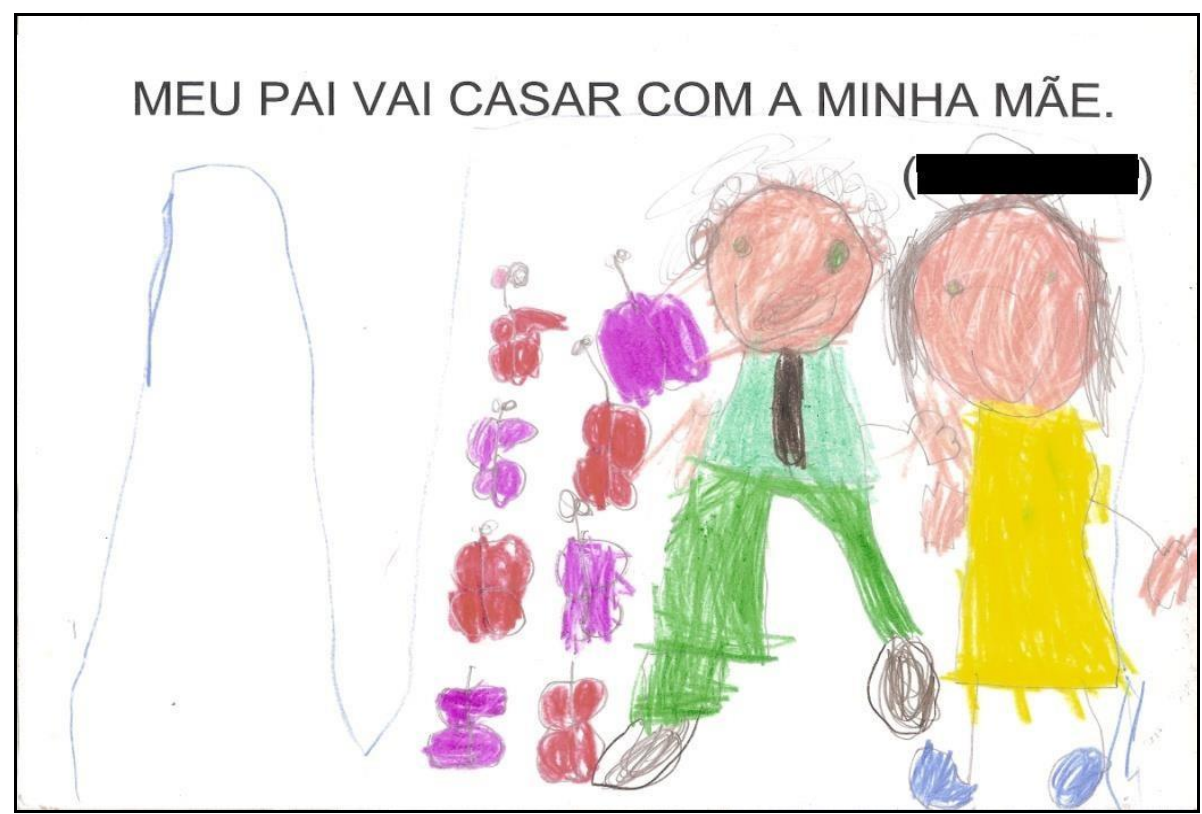

Fonte: Acervo pessoal das pesquisadoras.

Essa imagem motiva-nos a trazer uma situação do diário de bordo reveladora do envolvimento das crianças e da professora pesquisadora, assim como denotativa de como o grupo organizava o Jornal Escolar para mostrar aos familiares, conforme destacamos abaixo. Na situação apresentada, cada criança deveria encontrar a sua notícia, caso tivesse, ou escolher a de um amigo. Na conversa entre a professora pesquisadora e uma criança, vejamos como as crianças parecem envolvidas no processo, bem como utilizam a memória, a atenção, a comunicação e os conhecimentos sobre a escrita e a leitura:

$[\ldots]$

Professora pesquisadora:

- de quem foi a notícia que você escolheu, GMO?

GMO (acertando as folhas uma sobre as outras):

- A do Arthur.

Professora pesquisadora:

- A do Arthur?

GMO: - É.

Professora pesquisadora:

- E qual é a notícia do Arthur?

GMO levanta as folha, uma a uma, para procurar.

Arthur (ao lado de GMO) fala baixinho:

- Eu não tenho notícia.

GMO continua procurando entre as folhas a notícia de Arthur (que dias antes, havia sido escrita na lousa e ido para votação, porém não 
fora escolhida para o registro).

Professora pesquisadora:

- Tem uma notícia do Arthur aí, Gu?

GMO (chegando ao final das folhas)anuncia:

- Acabô.

Professora pesquisadora:

- Não tem?

GMO (envergonhado): - Não.

Professora pesquisadora:

- Então de quem é a notícia que você pôs em cima aí?

GMO (ainda envergonhado, falando baixo e com a cabeça abaixada):

- A da Ana Cláudia.

Professora pesquisadora:

- Da Ana Cláudia? GMO: - É.

Professora pesquisadora:

- Como você sabe que é da Ana Cláudia?

GMO (organizando suas folhas):

- Tá escrito aqui.

Professora pesquisadora:

- Tá escrito onde?

GMO (Passando o dedo sobre o nome da colega): - Aqui.

Além das duas técnicas da roda de conversa e do jornal da turma, as aulas passeios consistem em momentos de interação fora do espaço físico da escola e foram propostas desenvolvidas na pesquisa ora discutida. Foram realizadas aulas passeios no próprio bairro: dandoa volta no quarteirão da escola, idas aos Correios, à praça, ao supermercado, à feira-livre, pelas ruas do bairro para observações específicas, como a realizada na florada dos Ipês Amarelos, passeios que não demandavam transporte.

Em outras ocasiões, foram feitas aulas passeios com necessidade de transporte, indo aos parques da cidade - Anilinas (espaço público localizado no Centro da cidade) e Cotia-Pará (espaço público localizado à Rodovia Anchieta, km 55) -, ao cinema na cidade de Santos/SP, ao Aquário Municipal de Santos/SP e ao Zoológico de São Paulo/SP.

Esses momentos representaram situações de interação entre as crianças e a busca de conhecimentos e informações. Cada aula planejada era explorada em suas possibilidades de comunicação com as famílias, na elaboração de bilhetes e informativos, e nos registros posteriores feitos com as crianças. Nesses momentos de comunicação e registro, os textos eram expressos pelas crianças e escritos pela professora pesquisadora.

Os textos gerados após as aulas passeios constituem-se relatórios que trazem as compreensões das crianças sobre aquilo que viram no passeio.

A organização interna da sala de referência da turma se fazia pela organização 
cooperativa em cantos de trabalho, que eram propostos às crianças na Roda de Conversa e organizados diariamente pelas próprias crianças.

Geralmente, eram organizados cinco cantos. Alguns desses cantos eram permanentes, como o Canto da Leitura - que tinha duas prateleiras com livros de Literatura Infantil, revistas e gibis -, o Canto dos Jogos - composto por jogos de trilhas, dominós, quebra-cabeças, jogos da memória com imagens e sons -, o Canto do Desenho Livre - com folhas de diferentes tamanhos e cores, giz de cera, lápis de cor, canetas hidrográficas. Os demais cantos, geralmente, estavam associados aos projetos da turma e variavam também quanto aos materiais utilizados conforme as propostas. $\mathrm{Na}$ figura 04 , as crianças se organizaram em grupos para a realização de cada uma das atividades propostas a partir dos cantos.

Figura 04: Crianças envolvidas em Cantos de Trabalho Cantos de trabalho diversos na sala de referência da turma

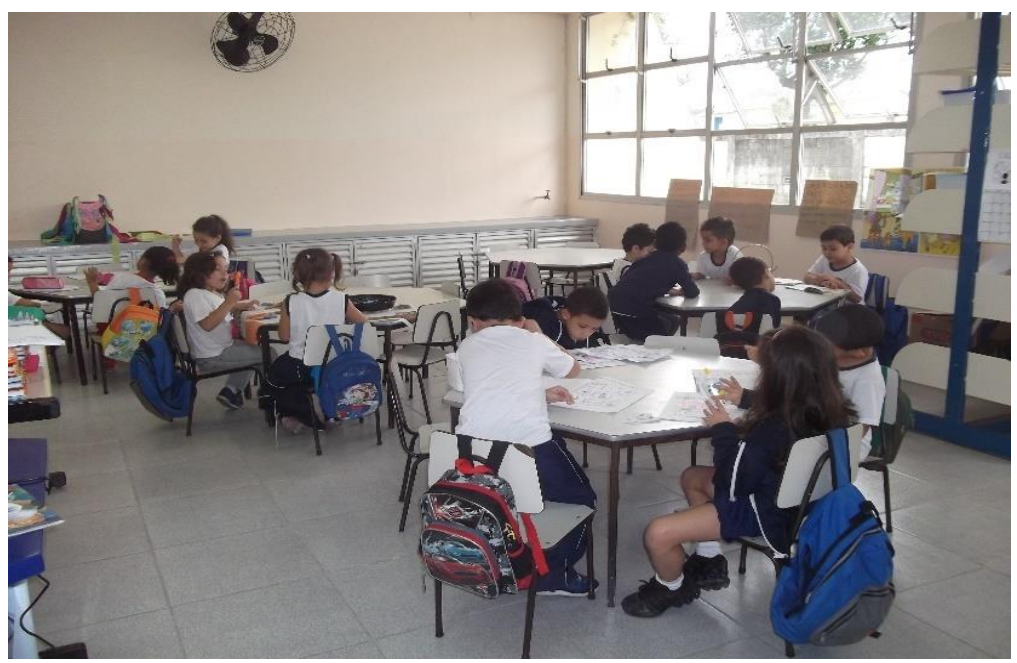

Fonte: Acervo pessoal das pesquisadoras.

No trabalho em Cantos, as crianças têm autonomia e cooperação, e o professor tem maior disponibilidade para observação e auxílio de grupos menores de crianças, possibilitando a oferta de maior atenção e escuta. O trabalho de organização do canto e de reorganização da sala é gradualmente assumido pelas crianças que vão conhecendo os espaços e as formas de organização, de forma que no início necessitam de maior apoio do professor e aos poucos se independem.

As crianças estavam trabalhando em diferentes cantos (modelagem com massinha, jogos, desenho livre, Leitura) JFS (seis anos e dois meses) fazendo um desenho livre conversa com os colegas sobre a informação que os correspondentes escreveram ["A nossa cidade é muito bonita tem muitas árvores e tem também um rio chamado Rio 
Pardo onde tem a corrida de boia que é muito divertida."]:

JFS: - Meu pai vai me levar lá em Santa Cruz... quando ele vim vou pedir pra ele.

ALVB: - Pra que cê quer ir lá?

JFS - Vou descer o rio de boia... já tenho a boia.

ACVC: - No rio é perigoso.

JFS: - Eu acho que é legal! Deve ser bem legal.

Nesta situação, as crianças parecem tranquilas para escolher o que farão no canto do desenho e aproveitam uma informação aprendida na realização de outra técnica para conversarem. Evidenciam a articulação de conhecimentos aprendidos, de maneira a vivenciá-los e comentá-los.

Outra técnica, é O Livro da Vida que consiste no registro cotidiano das nossas ações e observações sobre a vida da turma. É um registro escrito pela professora pesquisadora e desenhado pelos ajudantes do dia. As falas das crianças demonstram o envolvimento com o registro do que foi vivido e compreendido por elas. Geralmente, é elaborado em folhas grandes (tamanho A3) para que haja espaço suficiente para diferentes formas de registro: escrito, desenhado, fotografado, dentre outros.

Inicialmente, durante a produção de dados, esse registro não contou com envolvimento e animação das crianças. Seus primeiros registros apresentavam as marcas da rotina estabelecida, de forma que as crianças diziam-na para o registro. Com o passar dos meses e a ação intencional da professora pesquisadora de indicar às crianças que o registro de dias anteriores poderia ser retomado para lembrarmos algo e revermos fotografias, foram sendo reveladas às crianças as possibilidades desse registro que passou a se constituir rotina.

O registro no Livro da Vida geralmente acontece na Roda de Conversa final, na qual se avalia o dia e as proposições cumpridas ou não. Aos poucos, esse registro passa a trazer marcas da vivência coletiva e das interações, registrando sentimentos e emoções vividas pelo grupo, como demonstra a figura 05 : 
Figura 05: Página do Livro da Vida da turma de 2012 - Livro da Vida da turma de 2012, com destaque para o dia 10 de setembro.

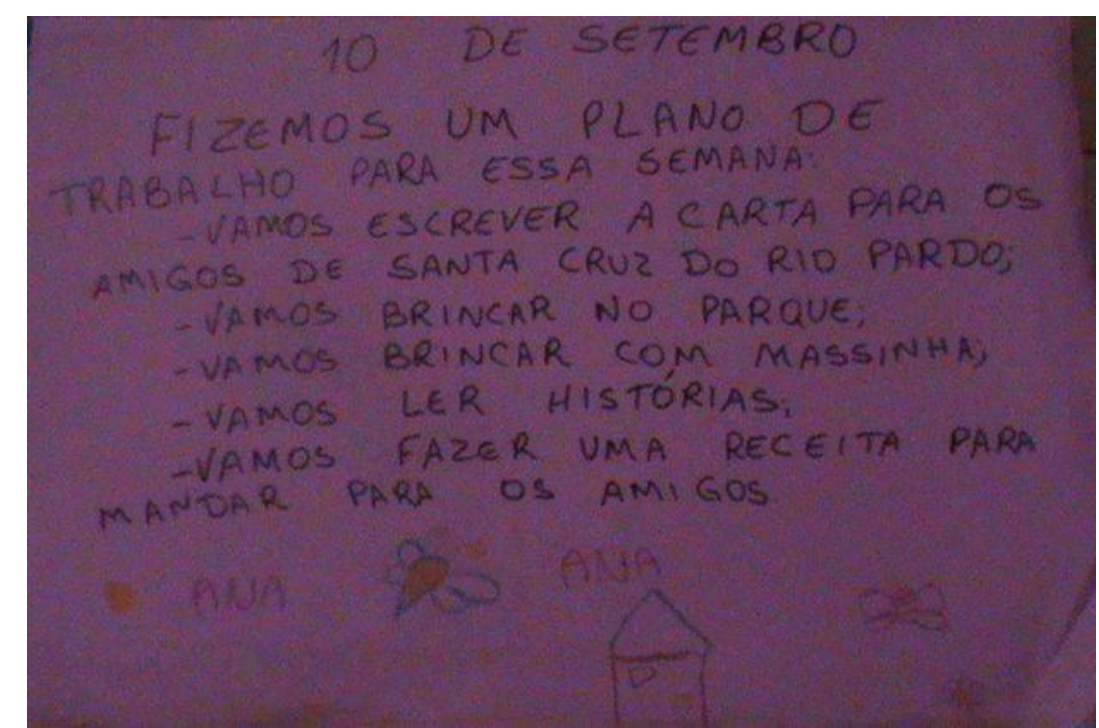

Fonte: Acervo pessoal das pesquisadoras.

O livro da Vida se constitui, conforme retratado, numa possibilidade de documentação e registro daquilo que as crianças vivenciaram na escola. Serve também para recordarem o vivenciado, compartilhares informações com a direção da escola, familiares, outras turmas, dentre outros.

Articulado a todas as técnicas Freinet, o trabalho diário na atividade infantil centra-se nos Projetos desenvolvidos pela turma. Esses projetos podem representar o interesse geral das crianças ou o interesse de um pequeno grupo de crianças.

No ano de 2011, a turma trabalhou com vários projetos. O projeto "Animais" foi elaborado institucionalmente e consistia num estudo realizado pelas diferentes classes da escola sobre o mesmo tema, que culminou na apresentação de encerramento das atividades letivas. O projeto "Sol” se desenvolveu a partir das discussões corriqueiras acerca do sol e suas representações; iniciou-se após a observação e discussão sobre o sol ser "menina ou menino", e, após o registro das dúvidas, desdobrou-se em vários subprojetos que se articulavam e possibilitavam às crianças um aprendizado envolvente e criativo.

No ano de 2012, trabalhamos com maior autonomia em relação aos projetos, não realizando projetos institucionais. No entanto, houve a articulação entre turmas em projetos menores, como a confecção de um livro-brinquedo, surgido após o conhecimento de um livro-brinquedo trazido da Brinquedoteca da UNESP/Campus de Marília pela professora pesquisadora; e o projeto Sanduíche da Maricota, surgido com a 
proposição às crianças de fazerem sanduíches após a leitura do livro "Sanduíche da Maricota", de Silvio Guedes; entre outros.

Os projetos de trabalho constituem-se, nessa perspectiva, como ferramenta essencial de trabalho com as técnicas Freinet. Por meio deles, o conhecimento se torna vivo, se impulsiona pelo interesse das crianças e pela necessidade que se instaura de saber e conhecer.

Assim, as propostas da Pedagogia Freinet vão ao encontro de um trabalho que se deseja para uma perspectiva de formação humana pautada na cooperação, autonomia, interação, atuação ativa de professora e crianças.

\section{Palavras finais...}

Neste artigo, nosso objetivo foi o de trazer à discussão princípios e técnicas de ensino organizadas, desenvolvidas e socializadas por Freinet (1976), com a perspectiva de refletir sobre como a Pedagogia pensada por este estudioso é fonte de participação ativa de adultos (professores) e crianças no ambiente escolar, desde a Educação Infantil.

Valemo-nos de resultados de tese de doutoramento recentemente finalizada (SILVA, 2016), ressaltando, nos limites deste texto, o rico teor das vivências da professora-pesquisadora e suas crianças para pensarmos práticas potencialmente humanizadoras e envolventes.

Em nossa tentativa de atualização das ideias e técnicas de Freinet (1976), as páginas anteriores retrataram como a roda de conversa, as aulas passeio, o jornal escolar, o livro da vida, os cantos de trabalho e os projetos podem materializar o planejamento pedagógico motivador do feliz encontro das crianças com os objetos da cultura e com outras pessoas (adultos e crianças) tecendo relações sociais em que os aprendizados conduzem formas sofisticadas de desenvolvimento pleno e integral na infância.

Do exposto e nos limites deste texto, nas páginas anteriores destacamos perspectivas da Pedagogia Freinet para pensar a escola atual, seus desafios complexos e contemporâneos, em busca de que seus princípios e técnicas sejam objeto de estudos, pesquisa e práticas e tornem-se fundamentos orientadores da educação escolar, considerando seus condicionantes externos e internos, de maneira a constituí-la num processo em que crianças, jovens e adultos tornem-se cada vez mais humanos. 


\section{Referências}

FRANCO, M. A. S. Pedagogia da pesquisa-ação. In: Educação e Pesquisa, São Paulo, v.31, n.3, p. 483 - 502, set./dez. 2005.

FREINET, C. As Técnicas Freinet da Escola Moderna. Lisboa: Estampa, 1976.

FREINET, E. Nascimento de uma Pedagogia Popular: os métodos Freinet. Tradução: Rosália Cruz. Lisboa: Editorial Estampa, Lda,1978.

ICEM, Primeiros contatos com a Pedagogia Freinet. Dossiê Pedagógico da revista L'Educateur. Tradução: Ruth Joffily Dias, 1979.

MELlO, R. R. Pedagogia Freinet: Um Caminho para uma Educação Ativa. São Carlos: Universidade Federal de São Carlos, dissertação de mestrado, 1992.

PODDIÁKOV, N. Sobre el problema del desarrollo del pensamento em los preescolares. In.:DAVIDOV, V.; SHUARE, M. La Psicologia Evolutiva e Pedagogica en la URSS (Antropologia). Moscou: Editorial Progresso, 1987. p.168172.

SAMPAIO, R. M. W. Ferreira. Freinet: evolução histórica e atualidades. 2.ed. São Paulo: Scipione, 1994.

SILVA, A. L. R. da. Leitura na Educação Infantil: Implicações da Teoria HistóricoCultural.Tese (Doutorado em Educação). Universidade Estadual Paulista, UNESP, Marília, 2016.

\section{Como referenciar este artigo}

SILVA, Ana Laura Ribeiro da, et al. Pedagogia Freinet e a escola no século XXI: perspectivas humanizadoras para o trabalho pedagógico. Revista Ibero-Americana de Estudos em Educação, Araraquara, v. 12, n. esp. 1, p.669-687, 2017. Disponível em: <http://dx.doi.org/10.21723/riaee.v12.n.esp.1.2017.9632>. E-ISSN: 1982-5587.

Submetido em: 30/03/2017

Aprovado em: 11/04/2017 